\title{
THE USE OF POLITICAL CARTOONS DURING POPULAR PROTESTS: THE CASE OF THE 2011 TUNISIAN UPRISING
}

\author{
Chaker Ali Mhamd \\ The University of Manouba, Tunisia \\ Al Buraimi University College, Oman \\ shaker@buc.edu.om
}

\begin{abstract}
This study investigates the use of political cartoons in the Tunisian context during its transitory phase in the aftermath of the 2011 uprising. It explores how political cartoons were used to critically reflect the socioeconomic and geopolitical conditions in Tunisia at that time. Additionally, it analyzes the predominant themes of Tunisian political cartoons during the transitory phase. To address these two research questions, this study uses a qualitative approach to analyze selected samples of political cartoons focusing on textual and graphic elements. The methodology adopted in this paper also employs textual analysis drawing upon semiotic theory addressing the framing of pictures, systems of signs, and visual aspects and modes of presentation.
\end{abstract}

Keywords: Political cartoons, media discourse, graphic text, visual representation, Tunisian uprising, Arab Spring. 


\title{
EL USO DE CARICATURAS POLÍTICAS DURANTE LAS PROTESTAS POPULARES: EL CASO DEL LEVANTAMIENTO TUNECINO DE 2011
}

\begin{abstract}
RESUMEN. Este estudio investiga el uso de las caricaturas politicas en el contexto tunecino durante la fase transitoria que siguió al levantamiento popular de 2011. Explora cómo se utilizaron estas caricaturas para reflejar de forma crítica las condiciones socioeconómicas y geopolíticas en Túnez en ese momento. Además, analiza los temas predominantes en dichas caricaturas politicas durante esa etapa transitoria. Estas dos cuestiones de investigación se abordan mediante un enfoque cualitativo que permite analizar muestras seleccionadas de caricaturas políticas centrándose en elementos textuales y gráficos. La metodología adoptada en este artículo también recurre al análisis textual de la teoría semiótica abordando la enmarcación de imágenes, sistemas de signos, y aspectos visuales y modos de presentación.
\end{abstract}

Palabras clave: Caricaturas políticas, discurso mediático, textos gráfico, representación visual, levantamiento tunecino, primavera árabe.

Received 26 June 2016

Revised version accepted 29 January 2017

\section{INTRODUCTION}

Comics and related media such as cartoons, graffiti, and posters have frequently been effective tools to transmit political messages in a playful manner. The power of the visual medium has played a significant role in influencing public opinions and protests. Prevalent in demonstrations, revolutions, and popular protests throughout history to the recent so-called "Arab Spring," cartoons have featured as a satirical form of communication.

The term cartoon "refers first to metaphorical codification and second to a satirical or humorous genre through which a cartoonist subtly informs, criticizes and entertains his audience" (El Refaie 2009: 181). More specifically, political cartoons represent a form of media discourse that uses verbal and non-verbal signs to disseminate information and express ideas and opinions on contemporary issues. Though political cartoons do not occupy large portions of the media, they can have a huge impact on the audience and/or readership as they effectively and humorously convey messages succinctly. They function as communicative devices in society and play a paramount role in influencing public discourse, especially during periods of political turmoil and popular protest. 
Very often, political cartoons have enabled audiences to look critically at their socioeconomic and political reality. In many instances, political cartoons prove to be more effective in disseminating information and demonstrating ideas than verbal texts, which usually require more time from both writers and readers. Cartoons communicate messages and critiques camouflaged as humour. These aspects of cartoons allow them to attract more attention and raise more curiosity, especially in countries where journalism and freedom of the press can face strict censorship.

Through cartoons, cartoonists try to respond to current socioeconomic and geopolitical issues in a humorous and satirical manner that can be read and understood quickly and directly. In fact, cartoonists try to translate the current events into culturally familiar signs and symbols that are locally and, sometimes globally, recognized. In times of crises and popular protests, these satirical symbols have direct impact on public opinion and social protests on the street. Accordingly, this paper seeks to explore how political cartoons can be used to understand and criticize socioeconomic and political processes in the Tunisian context in the aftermath of the revolution of January 14, 2011.

\section{LITERATURE REVIEW}

It is evident that contemporary mass media have become a prevailing channel of communication that catches the attention of the public using verbal and non-verbal elements as tools to express opinions and thoughts from a certain point of view (Mhamdi 2016). This communicative aspect has made media discourse a viable and compelling field of research. During recent decades, researchers have been investigating the use of language in different genres to achieve communicative tasks (Greenberg 2002: 183). More precisely, studying various approaches to language in its different connections with media enables researchers to explore the use of language in depth to help disseminate information and a mutual understanding of socioeconomic, geopolitical, and other events in a certain society. Thus, news media play a mediating role between events and news creators on one side, and the receivers and consumers of news on the other (Mhamdi 2017a).

Cartoons, as a type of media discourse, are a form of social artifact used to focus on the use of language in society to mirror social realities (Giarelli and Tulman 2003). Specifically, "using language resources to attract public attention and interest by the media, journalists, especially cartoonists, harness both linguistic and non-linguistic elements ingeniously and persuasively to create effect in a literary or dramatic passion and to evoke a particular response from readers" (Sani et al 2012a: 53). For Sani et al (2012a), political cartoons are 
considered to be graphically illustrated in a single visual frame and accompanied frequently by written texts or thought bubbles in a form of dialogue.

Distinguishing cartoons from comics, Samson and Huber state that "the style of cartoon is mostly characterized by simple lines, exaggerated features, as well as sketch-like and simplified figures. Comics are more oriented towards stories, their artwork is detailed, anatomically correct, and the drawing often closely resembles reality" (2007: 2).

To be politically powerful, authoritarian regimes seek to have control over visual production and consumption (Khatib 2013: 1). Due to the power of the political cartoon genre, which permits the use of linguistic and nonlinguistic cues, cartoonists express their thoughts and points of view regarding current socioeconomic and political issues through which social agendas are set (Greenberg 2002: 182). Political cartoons, therefore, function as communicative tools in society. They form a distinctive media genre with their own history, specific styles, conventions, and communicative aims (El Refaie 2009: 181).

Recently, there has been a growing interest in political cartoons across various disciplines such as sociology, psychology, communication and education (Greenberg 2002: 181-182). The increasing focus on political cartoons suggests that they are an established genre within media discourse. From a historical perspective, Benjamin Franklin was said to have originally started editorial cartooning when he first published an editorial cartoon in an American newspaper depicting an image of a snake dissected portraying the popular "Join or Die" slogan to encourage a united front against British colonialism (Burns 2007: 526).

Political cartoons appeared as an influential social medium due to the wealth of meanings and forms they embed. The textual and visual messages contained in political cartoons have a social impact that is derived from the simultaneous appeal "to the intellect and emotion" (Gocek 1998). In this same line of thought, it is contended that "consideration of the multimodel nature of the clues for ironical intention is essential for a proper evaluation of the clues used to signal irony" (Attardo et al 2003: 257).

Medhurst and DeSousa identify four main themes common to political cartoons. These are politically common places, cultural allusions, situations, and personal character traits (1981). According to Morris, cartoon portrayals are always satirical and comparable to armaments launching attacks on political leaders (1992). Using symbolic convergence theory, Benoit et al analyze political cartoons depicting the Clinton-Lewinsky affair (2001). The sample used 2000 cartoons covering public and media reaction to the American president. The analysis revealed the satirical portrayal of Clinton and the enormity of the scandal. 
Conners investigated the use of political cartoons in the context of the 2004 US presidential election campaigns (2005). His findings reveal that political cartoons were used to manipulate voters' choices among the candidates; that in general, in election periods, cartoons are used by the campaign machinery to channel public in favor of one candidate over others. These findings question the role of policy makers in manipulating cartoonists due to their influential role whether as challengers to governments or gatekeepers to them.

Stouter et al. explore the process of writing and editing cartoons in terms of the role they play in society (2008). The findings further endorse the direct impact that graphic illustrations have on their audience. Employing a multimodal theory of humour, Tsakona tackled the issue of language and interaction in cartoons (2009). Focusing on the verbal and visual elements of cartoons, the researcher contends that cartoon humor is a complex process, which includes various mechanisms of interplay between linguistic and non-linguistic elements. The findings recall El-Refaie argument that "visual metaphors cannot be described adequately in formal terms only. Rather, they must be considered as visual representations of metaphorical thoughts or concepts" (2003: 75).

Eko studied how four African political leaders had been dehumanized in the post-Cold War era by a number of African newspapers through the use of political cartoons (2007). Another study that focused on the African context is that of Sani et al., which investigated "the linguistic elements used in the cartoon written texts to illustrate how Nigerian cartoonists specifically use language to construct satire" (2012a: 52). Employing a perceptual theory of satire and critical-discourse analysis, Sani et al (2012a) identified lexical items in Nigerian cartoon texts and explored how Nigerian cartoonists create satirical impressions about political leaders.

In their second study of the Nigerian context, Sani et al. studied "the nature and function of humor in Nigerian political cartoons, using theoretical perspectives of humor as "a method of analysis" (2012b: 148). The findings suggest that the purpose of using humor in Nigerian political cartoons is to relieve audiences of politically stressful situations. Additionally, the study confirms previous findings that the use of political cartoons aims at persuading audiences and orienting them toward certain opinions about current issues in a particular society (159).

In the Arab world context, a novel and instructive perspective on the culture of the Arab world is presented by Mahfouz which utilizes Arab media cartoons to reflect the daily lives of Arab citizens. Analyzing the cartoons and how they interact with their context, Mahfouz explores the fundamental traits of Arab culture and simultaneously provokes readers to scrutinize their personal understanding and assumptions (2011). 
The so-called "Arab Spring" has recently been a focus of media and research attention. Khatib skillfully examines the importance of the visual aspect in the Middle East context (2012). The study explores the different ways the term "image politics" can be politically used and understood. The researcher explains that the visual includes a variety of elements encompassing "physical, electronic, nonelectronic virtual and embodied spaces" (Khatib 2012: 7). This understanding of the visual relates to current studies that perceive images as tools of resistance, counteraction, and activism (Mhamdi 2017b).

Totry and Medzini's influential study examines the use of political cartoons in popular protests to focus on socioeconomic and geopolitical issues by examining the works of the Palestinian cartoonist Nagi Al-Ali who was assassinated in 1987 (2013). The findings echo Mahfouz presentation of the Arab world cartoons culture as they reveal the potential of Arab political humour to mobilize public opinion and bring about regime change (2011). Drawing more than forty thousand cartoons that mostly address issues related to Palestinian-Israeli conflict, Al-Ali is perceived as one of the most influential Arab artists of the twentieth century (Wozniak 2014: 12).

In the same context, Wozniak tackles the issue of political humour to examine cartoons representing the so-called Arab Spring through the application of an image studies approach. Seeking to explore common themes addressed by cartoonists, the researcher presents the findings into categorized themes. Wozniak's investigation is one of the pioneering studies that address Arab political humour in the context of the so-called Arab Spring. Her findings mainly reveal that cartoons can be seen as "predictors, opinion changers or chronicles, not necessarily in terms of facts, but in terms of opinions" (2014: 22). She concludes by stating that Arab cartoonists seek to "teach a Tunisian lesson" that Arab citizens are capable of revolutions and uprisings against their authoritarian regimes. This conclusion is proves to be true after Arab dictators in Tunisia, Egypt, Libya, and Yamen were ousted one after the other.

Despite the considerable research on political cartoons, the Tunisian context seems underresearhed, as no research has specifically focused on the use of political cartoons and their impact on Tunisian audiences. In fact, this genre of media discourse has witnessed a remarkable growth in Tunisia especially in the aftermath of the revolution of January 14, 2011, which signaled the outbreak of the so-called "Arab Spring." This has made the Tunisian context a fertile field of research for political cartoons. This paper is an attempt to bridge this gap by building on previous studies and applying existing theories on the use of political cartoons for the Tunisian context.

The Tunisian context in this study refers to the aftermath of the Tunisian revolution which burst on December $17^{\text {th }}$, 2010, when Mohamed Bouazizi set 
himself on fire and which caused the ousting of the president Zine El Abidine Ben Ali on January $14^{\text {th }}$, 2011. In fact, the so-called "Arab Spring" started from Tunisia and then a series of uprisings spread across a number of Arab countries where some of them are still witnessing political turmoil and military unrest until today. The "Arab Spring" was the first time in history that events in the Arab world were reported through social media such as Facebook, Twitter, and YouTube. It is asserted that "The Arab Spring had many causes. One of these sources was social media and its power to put a human face on political oppression. Bouazizi's self-immolation was one of several stories told and retold on Facebook, Twitter, and YouTube in ways that inspired dissidents to organize protests, criticize their governments, and spread ideas about democracy" (Howard et al 2011: 2). Arab political cartoons witnessed a boom in the aftermath of the "Arab Spring" and Tunisia made no exception. It is argued that the "Arab Spring" represents the 'golden age' for political cartoonists (Wozniak 2004: 12).

\section{METHODOLOGY}

This paper seeks to answer two main research questions: first, what were the predominant themes of Tunisian political cartoons during the transitory phase after the revolution? Second, how were political cartoons used to reflect and criticize the socioeconomic and political plight of Tunisia in the aftermath the January 2011 revolution? To address these questions, data has been collected from a selection of online political cartoons that were frequently circulated and shared on Facebook users' accounts on the list of the researcher's Facebook account.

Since the outbreak of the Tunisian revolution on December 17, 2010, Facebook has become the main collective source of information and the most salient tool of communication for Tunisians. Sharing videos, pictures, and posts was the focal tool for interaction between them. This study explores the most shared cartoons among a sample of Tunisians during the Tunisian revolution and its aftermath. The age of the target population varied from 20 to 55 years old including male and female users. All the sample population is Tunisian individual and group Facebook users on the researcher's private account list. The posts have been collected by Facepager software, which is generally used to extract public data from social networking websites.

The frequency of posts that were shared during the period under study was measured through the application of a machine-learning algorithm that aims at identifying the number of times a post was shared by users. Although the extracted data revealed between 37 and 52 posts related to cartoons were shared among the sample population, only 16 cartoons were finally selected as corpus for this study. This selection was based on the researcher's decision to consider a post 
to be "frequently shared" only if it is shared by more than $50 \%$ of the sample population. Any post that was shared by less than $50 \%$ of the sample population was removed from the corpus and considered negligible.

It is worth mentioning that the corpus of the 16 cartoons investigated in this study includes texts and terms in three languages: Arabic, French, and English. The reason behind using Arabic and French is obvious as Tunisia is an Arabic-speaking country that is also a francophone member. Having been a French colony from 1881 to 1956, Tunisia has ever since established strong ties with France where French is the second language in the country. French is heavily present in the Tunisian educational system and widely spoken in Tunisians' daily lives. However, Tunisian cartoonists do not commonly use English language. Nevertheless, the presence of some English terms in a number of the sample cartoons in this study may be due to the wider context where the cartoons were developed and then frequently shared online.

In fact, the Tunisian revolution outburst on December 17, 2010, with no clear outcomes looming ahead. Because of the government strict control of media at that time, Tunisians had no other choice than to use social media to spread their opinions and make their voices heard in order to fight for their cause. Therefore, the use of English may be understood as a tool to reach international community and let the world know about what is taking place in Tunisia. The resort to a few English terms was a way to gain international community sympathy and support and to counter react to the mainstream media discourse, which was favouring the government official presentation of events taking place in Tunisia at that time.

The study uses qualitative approach to analyze the samples. Cartoon texts in this context were used as units of analysis where the main variables of interest to this study include the linguistic textual and graphic elements of the political cartoons under investigation. More specifically, content analysis was employed to explore the content of cartoon texts selected for analysis (Kress and Van-Leeuwen 2006). The selection of the sample is based on the frequency of appearance and circulation on individual and group Facebook pages and accounts. It is worth noting that the focus of this paper is not on the cartoonists who originated the 16 political cartoons which represent the sample of this study, but rather the focus is on the main themes tackled by the cartoons and how various mechanisms of interplay between linguistic textual and graphic elements intermingled satirically to represent the socio- economic and political conditions in the aftermath of the 2011 Tunisian uprising.

Though the focus of this investigation is not on cartoonists, it is evident that cartoons do not spring from void, but they are rather the artistic materialization of cartoonists' identities, ideologies, thoughts, visions, and origins. Cartoons function in a mutual relation and interplay with their context where they impact, and 
are impacted by, the wider context. For this reason, it is indispensable to note that all the cartoons belong to Tunisian cartoonists and they were shared on Facebook accounts of Tunisian users. Additionally, these cartoons were produced, and then shared, as soon as the Tunisian uprising burst. The cartoonists, being Tunisian citizens living in the same socio-political context and witnessing the same conditions, especially the historical moment of ousting the Tunisian president, have reacted to this changing context.

Media scholars have built on Saussure's concept of the sign, consisting of the signifier and signified whose outcome are codes that serve representational functions. In this respect, Fairclough states that "written texts in contemporary society are increasingly becoming more visual (...) not only in the sense that newspapers, for instance, combine words with photographs (...) but also because considerations of layout and visual impact are increasingly salient in the design of a written page" (1995: 17). In this same line of thought, Kress and VanLeeuwen argue that "language always has to be realized through, and comes in the company of, other semiotic modes"; clarifying that "any form of text analysis which ignores this will not be able to account for all the meanings expressed in texts" (1998: 186). Accordingly, the analysis of the selected political cartoons must acknowledge the complexity of reading cartoons posed by their semiotic sophistication. Texts and images are integrated in a way that compels readers to negotiate and decode both verbal and non-verbal codes to generate meaning. For this reason, the methodology adopted in this paper will also employ textual analysis drawing upon semiotic theory. Semiotic analysis of the sample cartoons in this study entails addressing the framing of pictures, systems of signs, style of drawing, use or absence of color, page layout, and all other visual aspects and modes of presentation (Hutcheon 1994; McCloud 1993).

Critics of cartoons and comics argue that readers/viewers play a paramount role in interpreting the encoded content. Scott McCloud and Thierry Groensteen affirm that cartoons entail more interpretation than prose (1993: 28). Actually, readers play a crucial role in reading beyond the cartoon where meaning awaits further exploration to seek "closure" (McCloud 1993: 90).

The analysis of the 16 political cartoons rests upon theorists as Scott McCloud, Thierry Groensteen, Charles Hatfield, and Will Eisner. Accordingly, a close investigation of the components of the cartoons such as the framing of pictures, systems of signs, layout, border strips, comic styles and visual aspects and modes of presentation is necessary for the interpretation. This method of approaching political cartoons is similarly advocated by what has been referred to as Groensteen calls "pertinent contextual rapports" (Groensteen 2007) and a creation of a "grammar of comics" (Eisner 2008: 19; McCloud 1993: 5). 
The spatio-topical apparatus of political cartoons imposes on the reader an active involvement in the creation of meaning. Essentially, this study is genuinely concerned with the dynamic role of the reader as a significant constituent of the cartoons interpretive process. It is the historical context of the drawing and the circulations of cartoons that determine readers' interpretation. In this context, Reader Reception Theory is deemed to be an indispensable theoretical tool upon which the analysis rests. The analysis is primarily directed through Hans-Georg Gadmer's "historical situatedness" (Selden 1989: 95). Consequently, time and historical elements are crucially important in the interpretive process, especially that the circulation of the 16 political cartoons took place during a post-revolutionary Tunisia.

The methodology used for analysis provides a framework for understanding the language, tone, and themes indicated by linguistic and non-linguistic cues as advocated by Hutcheon (1994) and McCloud (1993). It also permits the examination of cartoon text content against the broader socioeconomic and political context of Tunisia during the transitory phase of the aftermath of the 2011 revolution. This historical moment has made the politics of Tunisia more visible than ever especially that social media offered oppositional parties and groups as well as ordinary individuals unprecedented opportunities to use images and videos where they are not only heard, but most importantly, seen (Khatib 2013). It is argued that "language and visual communication can both be used to realize the 'same' fundamental systems of meaning that constitute our culture, but each does so by its own specific forms, do so differently, and independently" (Kress and Van-Leeuwen 2006: 19).

During the Tunisian revolution and its aftermath, Tunisian Facebook users had a widespread tendency to share news, thoughts, and feelings and to exchange information about their neighborhoods. Facebook was the most effective medium of communication for Tunisians at that crucial time and posting pictures, videos, and cartoons and sharing these posts became a collective daily practice. On Facebook accounts, Tunisian people had an unprecedented opportunity to express themselves freely, to transcend boundaries, and to call for freedom, social justice and regime change. Political cartoons are said to play an important role in such circumstances. Therefore, the analysis of political cartons in the Tunisian context of the 2011 revolution and its aftermath is the focus of this study.

\section{ANALYSIS AND DISCUSSION}

The analysis of the political cartoons sampled in this study will be presented and discussed through the identification of the thematic issues subsumed in the cartoons and a semiotic investigation that highlights the framing of pictures, systems of signs, 
and style of drawing. The content and semiotic analyses of the selected sample of the political cartoons that were circulated and shared by Tunisian Facebook users revealed the emergence of eight main themes prevalent in Tunisian media, political parties, and public interest in the aftermath of January 2011 revolution. The focus of political cartoons on those eight themes made them a common interest for the Tunisian public during the transitory phase in the aftermath of January 2011 revolution.

\subsection{THEME 1: OUSTING PRESIDENT ZINE EL ABIDINE BEN ALI}

Following the uprising in Tunisia from December 17, 2010 to January 14, 2011, the ousting of Tunisian president Zine El Abidine Ben Ali, who left the country and fled to Saudi Arabia, represented a major event in Tunisian history. It received huge local and global media coverage, and political cartoonists were no exception. Cartoonists exploit the power of visual representation to turn abstract ideas into concrete illustrations that can be easily grasped by audiences. As shown in Figure 1 , one of the most frequently circulated cartoons among the sample, illustrated the idea that a successful revolution would finally free the Tunisian population from dictatorship and the authoritarian regime.

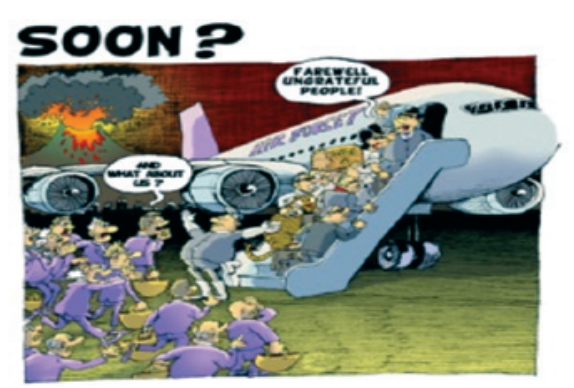

Figure 1. Soon? (Mhamdi 2014).

The analysis of a cartoon necessitates the exploration of its symbolic dimension, as Scott McCloud puts it, "details are very much concerned with pictorial representation" (1993: 141). Symbols, therefore, channel meaning and, in the context of the above figure, they mediate history and represent a national maturity. The above panel is, in fact, composed of two adjacent symbols that allegorically vehicle the rage of Tunisians vis a vis the political agenda of their president and the latter's defection from Tunisia. The volcanic eruption that occurs at the background of the panel symbolically imitates that of Tunisian people and it connotes political and social instability during which the "air force 7" accommodates the ousted president on the verge of fleeing to Saudi Arabia. 
The choice of the plane number, "air force 7", functions as a remainder of the president's early years of presidency when he took over power on $7^{\text {th }}$ November, 1987, change and social renewal that Ben Ali strongly related to the same number. The cartoonist sarcastically posits an irony of fate that attributed to the plane on which the ousted president will head to his final destination and exile that same number. The number " 7 " is thus endowed with a double layer of meaning, past power and actual loss.

This incident represented a historic moment that signaled the victory of the revolutionary Tunisians who succeeded in ousting their dictator. Such message is channeled mainly by the cartoon's "Mise en scene". Pascal Lefevre asserts that the "Mise en Scene" in comics "concerns the representation of a scene by a specific organization of its virtual but figurative elements such as décor, props, and characters" (2012: 71). For instance, Zine El Abidine Ben Ali is represented with a number of his family members boarding the plane and bidding his people farewell. The irony in this cartoon is that the group of people who are wearing purple and holding bags are asking "what about us?" Purple is the symbol of the political party of Zine El Abidine Ben Ali (Democratic Constitutional Rally) and the bags held by people are, in Tunisian culture, symbols of flattery.

The cartoon text "SOON" with the question mark refers to the surprisingly unexpected ousting of Ben Ali who left the country and the presidency in less than a month after the uprising burst

The cartoonist is, thereby, referring to the fate of the supporters of the president during his authoritarian and oppressive regime. These supporters are now left behind, while the president is fleeing with his family. The ex-president and his family members appear relaxed and comfortable with huge amounts of money as opposed to the crowd who appear worried and are prevented from boarding the plane by the police officer. It is implied that the supporters will face the anger of the revolutionaries and would be made accountable for the actions of Ben Ali's regime. Additionally, Figure 1 paves the way for the cartoons depicted in Figures 2 and 3 whose main theme is the freedom and liberty enjoyed by Tunisian people in the aftermath of Ben Ali's era.

\subsection{THEME 2: POLITICAL FREEDOM AND PERSONAL LIBERTY}

Figure 2 represents the expected and longed-for future that lies ahead for the Tunisian public after they successfully ousted their dictator. The Tunisian flag in the background image represents the whole country and its people, and the hands with broken shackles stand for the beginning of a new era of freedom and liberty for all Tunisians. Additionally, the absence of framing in figure 2 connotes the transgression of social and political barriers yearned for by Tunisians. 
Similarly, Figure 3 typically represents the freedom and peace that the Tunisian revolutionaries would achieve as the outcome of their uprising. The lunar image of the Tunisian flag, and the common man sitting in the corner, who finally frees a dove holding an olive leaf, motivates the readers' thoughts toward a positive expectation of a new era of peace and liberty. As figure three represents, liberty is born out of Bouaziz's wound, which is not only physical, but also social. Poverty drove the man to illegally sell vegetables in Sidi Bouzid's market. Following the confiscation of Bouazizi's goods by the local police, the loss of hope and social alienation pushed him to the edge of depression. The fall resides in the act of burning his body.

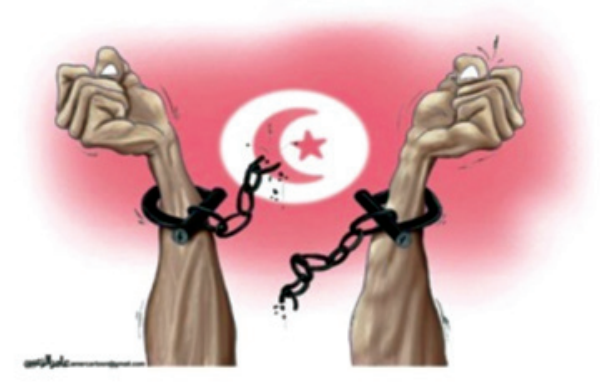

Figure 2. Freedom (Zaghbi 2011)

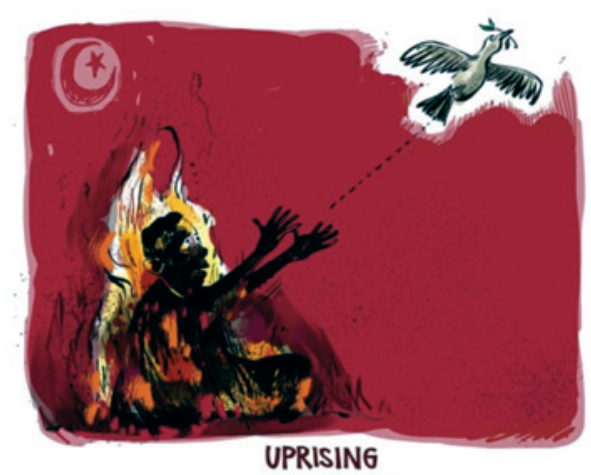

Figure 3. Uprising (Mhamdi 2014)

The overall symbolism of this cartoon is the dove of peace as a phoenix rising from the ashes of the suffering of the people, represented by the man in flames. Death bears the seeds of a new beginning hand a new life. Accordingly, in Figure 3, the caption "UPRISING" is given a powerful metaphorical meaning of the phoenix. 
In this way, both cartoons, signal the outbreak of a new era in Tunisian history following the ousting of Zine El Abidine Ben Ali on January $14^{\text {th }}$, 2011. Based on the connotations of both cartoons, there is a call for the Tunisian public to celebrate the outcome of the uprising, namely, political freedom and personal liberty, despite the gloomy atmosphere of suffering indicated by the use of red and dark colors.

\subsection{THEME 3: THE TUNISIAN ELECTIONS}

After January 14, 2011, a transitory phase began in Tunisia when the prime minister of Ben Ali's rule, Mohammed Gannouchi, assumed power for less than 24 hours. His temporary ascent to power was followed by the chairman of the parliament, Fouad Mbazaa, who assumed the presidency according to the Tunisian Constitution. This move was not appreciated by the Tunisian public as Mbazaa was known to have been an important figure in the ousted president's regime. Consequently, there was a call for presidential and parliamentary elections. That occurred when the Tunisian interim government, led by the then prime minister, Beji Kaid Sebsi, started preparing for the 2011 parliamentary elections from which the president would be elected by members of the democratically elected parliament.

The first Tunisian elections after the revolution received huge media coverage both locally and internationally. It was also the focus of many cartoonists who ironically sought to express their thoughts and ideas. The irony in figure 4 lies at the level of opposing between the "said" and the "unsaid" as Linda Hutcheon puts it (1994: 11). The panel opposes terrorism to the threat of democracy. Figure 4, for instance, presents a typical cartoon that tackled one of the most important issues which the interim government, parliament, and political parties were concerned of; namely, the looming terrorist threat, given the geopolitically uncertain conditions surrounding the country.

The cartoon in Figure 4 graphically depicts how democracy will defeat the hand of terrorism. It depicts a man with a long beard and a turban trying to block the Tunisian people's vote to capture the election box with his left hand, while a voter's hand with the Tunisian flag cuts the terrorist's arm with an election card. This act attributes motion to the cartoon transmitted through the terrorist's facial expressions indicating pain and suffering as a consequence of the democratic act of voting. It is worth mentioning that a huge number of local extremists were against the Tunisian elections and they tried to terrorize people and discourage them from taking part in the elections. The connotation of the cartoon signifies that the Tunisian public should fight the terrorist threat by participating in the elections. The cartoonist is calling for the conduct of free and fair elections that would constitute a major challenge to terrorism. There is 
a strong call for Tunisians to actively participate in the elections and give their voices to political leaders who would build a new democratic Tunisia.

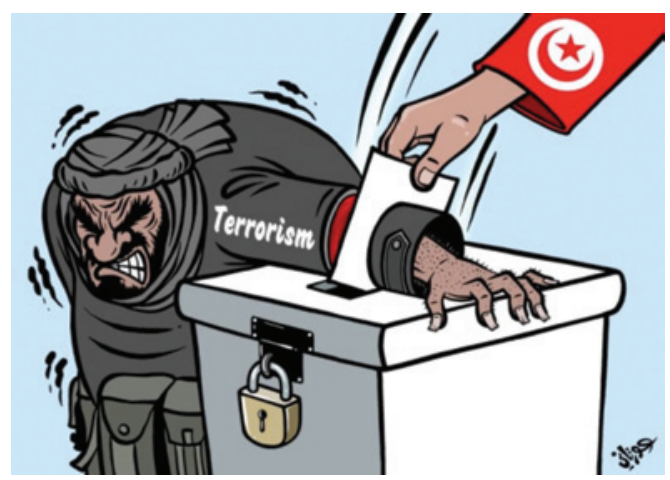

Figure 4. Elections (Ouerteni 2014).

However, there were also other themes that characterized cartoon representations of the Tunisian elections of 2011. The importance of participating in the elections as a means to fight terrorism was not the only theme tackled by cartoonists. A number of cartoons were concerned with the large number of political parties racing for the parliamentary election campaign. This confused the voters who felt uncertain as to how they should vote. The cartoon in Figure 5 entitled "Road to Elections" depicts an ordinary Tunisian puzzled by seven different road signs, symbolizing the uncertainty felt by Tunisian electors. Road signs are supposed to smooth the way and to clarify directions. Ironically, the cartoony figure stands in full confusion and loss which political vision to embrace.

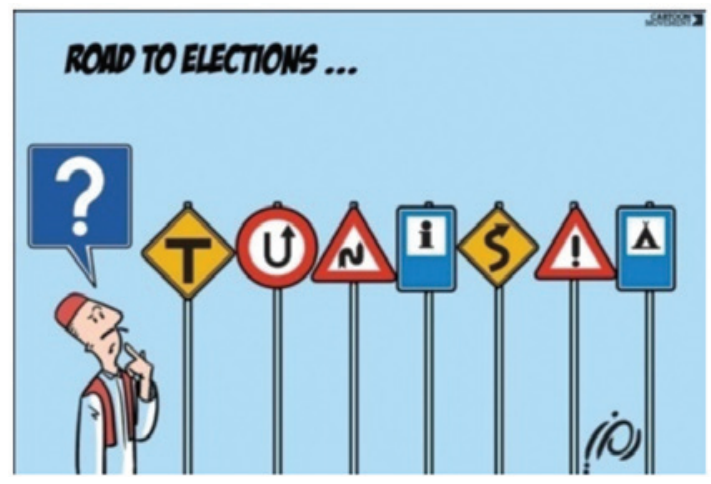

Figure 5. Road to Elections (Movement 2012). 
This exaggerated variety of political parties, the majority of which began after January 14, 2011, is the main reason for his hesitation. In fact, the proliferation of political parties was said to have discouraged Tunisian participation in the parliamentary elections. As the above figure allegorically channels, despite that all political parties are united under the umbrella of one country whose name is being formed by the signs themselves, their heterogeneous messages obscure the path in front of the electors.

\subsection{THEME 4: THREATS TO THE REVOLUTION}

One of the main themes that were the focus of many cartoons in the aftermath of 2011 revolution were the threats faced by the Tunisian revolution. There was concern that some local parties and a number of foreign countries would not support the uprising. The cartoon in Figure 6 satirizes the various threats facing the revolution, the only hope of the Tunisian working class and poor people for a better life, by portraying a working-class man holding a balloon that symbolizes the revolution but, unfortunately, he faces one of two fates: arrows or crocodiles. The written texts next to the five arrows denote the threats of external countries, supporters of the ousted president's regime, and the local bourgeoisie. The texts next to the crocodiles denote the threats of unemployment, poverty, corruption, coercion, violence, injustice, and cost of living. All the texts in Figure 6, whether in Arabic language or the name of the country U.S.A which is written in English, present the Tunisian public powerless before their fate and their only hope, the revolution, depicted as a fragile balloon, is also faced with many threats. The image of a balloon also represents an ideal and an idea that may not take flight in such a context where local and foreign threats are looming ahead.

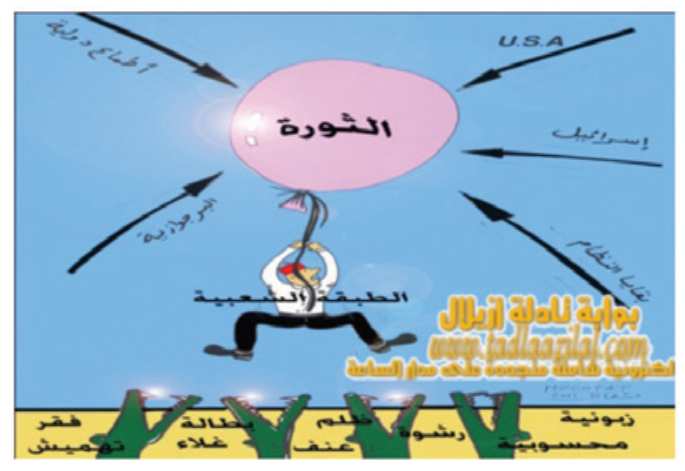

Figure 6. Revolution (Mechtat 2011). 
Additionally, the cartoon in Figure 7 also depicts external threats to the Tunisian revolution. The cartoonist portrays Tunisia as cake to be shared by five foreigners around a table with their plates, forks, and knives ready for the feast. From their clothes styles, it can be deduced that they are from Arab Gulf Region and Western countries. The characters' appearance reveal their geographical belonging and therefore, their agenda and political intentions are better illustrated through their greedy faces and unbridled lust for sharing the cake. Each of the five has money - a sign that they intend to pay local actors, including conspirators, corrupt officials, bourgeoisie, and vested interests, to secure their interests in the country. The cake with the Tunisian flag stands for the country being served by a police officer who represents the implication of the Ministry of Interior in this affair. The portrait on the wall corresponds to the president Zine El Abibidine Ben Ali and this is reinforced by the background which reveals where the scene is taking place, namely the presidential palace in Carthage. Though the president was ousted, the presence of his portrait with his face opposite to the round table in his presidential palace where the country is being served to foreigners is very symbolic. Furthermore, the caption represents the colorful logo of Tunisia in a similar way as the touristic leaflet, which indicates the exotic vision of the country by the various foreigners. This image is very revealing and it directly transmits the message of the cartoonist to the audience that Tunisia has become a shared land to be served to foreigners with the implication of local actors.

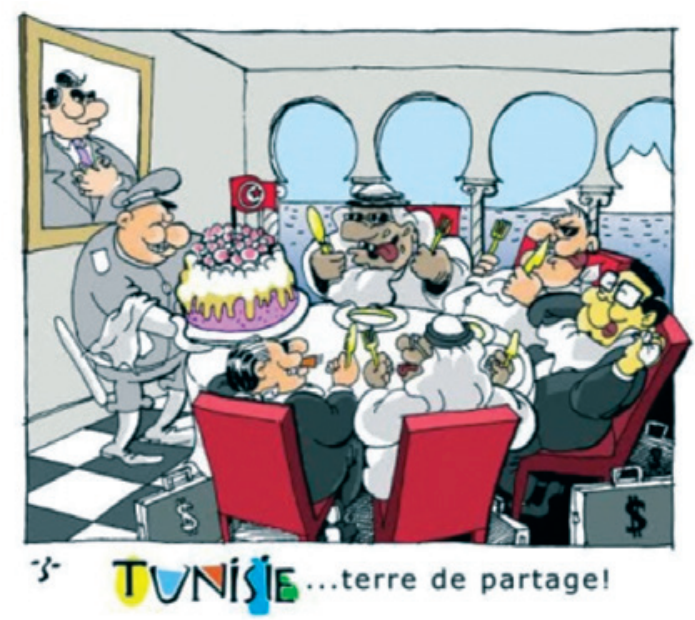

Figure 7. Tunisia: A Shared Land! (Mhamdi 2014). 


\subsection{THEME 5: THE THREAT OF TERRORISM AND RADICALISM}

With the rise of the Islamic party, Al-Nahdha, as the winner of the 2011 parliamentary elections, a new threat came to the forefront: the fear of political Islam, radicalism, and terrorism, especially from the geopolitical situation surrounding the country and the expansion of ISIS from Iraq to Syria and Libya. Following terrorist incidents of suicide bombings, the targeting of liberals, and the rise of radicalism, this threat became a reality. Tunisia has long been known for its open-mindedness, modernity, moderation and, after Lebanon, was considered one of the most modern Arab countries. The new radicalized status quo was a threat to that long history and the main victims would be future generations. Figure 8 depicts this new threat of Islamic radicalism and the brain-washing that targets younger generations. The cartoon is calling the attention of the audience toward this looming threat that may change aspects of Tunisian society. The visual metaphor being used is that of children on a production line being given blinkers. The focus of the cartoon is on children as they are easy targets and represent the future of the country. The clothing and general appearance of the man perpetrating the act reveal that he stands for the new wave of political Islam. He is a representative of Islamic ideologies intended to be ingrained in the minds and psychologies of the young generation. Additionally, it is worth noting that not a single female child is depicted in the cartoon which connotes the radicalists' perception of women which has always been degrading. As shown in Figure 8, the origin of the threat comes from radical Muslims.

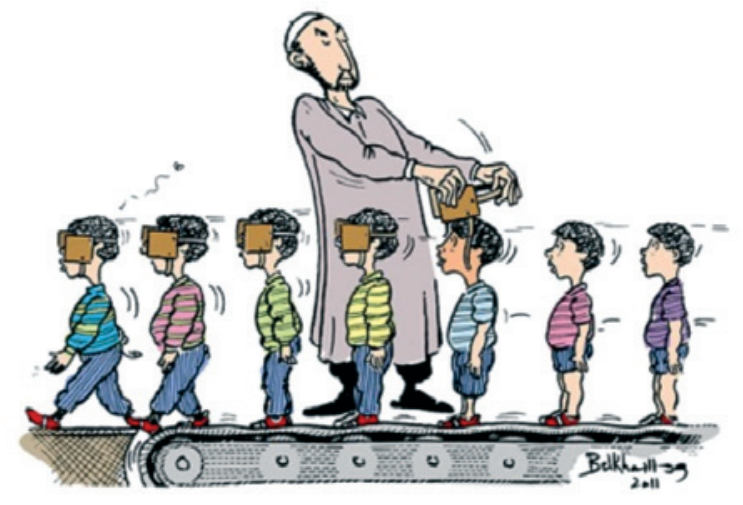

Figure 8. (Belkhadhi 2011). 
Radicalism and terrorism are perceived as genuine threats to the Tunisian Republic in its transitory phase. Cartoonists are trying to warn against these threats using satire and irony. The democratic rights and liberty of the Tunisian society are at risk and this is not what the majority of the revolutionaries had yearned for nor expected. The aims of the revolution were never to change Tunisia into a radicalized state nor relinquish the achievements of more than fifty years of secularism.

Figure 9 further symbolizes the deviations that took place after the 2011 revolution and the threats to Tunisian society. The cartoon represents an infamous Tunisian Islamist, Bechir Ben Hassan who, known for his radical views, called for a prohibition against women traveling alone, as is the case in Saudi Arabia. The cartoon symbolically represents a Tunisian woman wearing a burqa chained to Bechir Ben Hassan. The use of the woman's black clothing and the metallic chain is deliberate and signals the threat of losing women's rights, for which Tunisia has long been praised. The positioning of the woman in black chador in the background indicates the hidden intentions of political and religious preachers of the period. The female character is illustrated as the prisoner of the bearded male cartoon figure that humorously depicts Bechir Ben Hassan's vision of mapping spaces and instilling conditions concerning the voyage of women without a legal and mature male companion. The cartoon text states that "Bechir ben Hassan prohibits women from travelling alone". The textual and graphic texts call readers to be aware of what could result from radical preaching, with a focus on the plight of women's freedom.

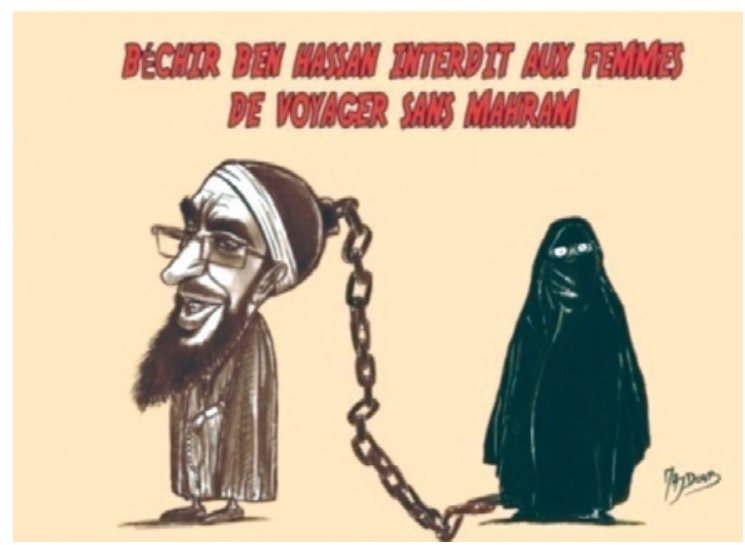

Figure 9. Bechir Ben Hassan Forbids Women to Travel without Mahram (Majdoub 2012). 


\subsection{THEME 6: FINANCIAL CORRUPTION}

Throughout Tunisian history, whether prior to, or in the aftermath of January 14, 2011, the issue of financial corruption among government officials has been a major concern. However, following the 2011 revolution, the topic of financial corruption was no longer taboo and, hence, this topic came to the forefront of media agendas. Political cartoonists seized this new level of freedom and tackled the issue both harshly and subtly.

Figure 10 represents three government officials and their boss, all with blocked ears and wearing black glasses. The text of the cartoon states the figures are "protectors of the public treasury," but with deaf ears and almost blind eyes the cartoonist's message is obvious. The choice of the black color for the glasses is symbolic as it elicits shortness of sight. This is an ironic image that depicts the opposite of the caption. The message is simply that these "protectors" are corrupt and represent the real danger to the public funds.

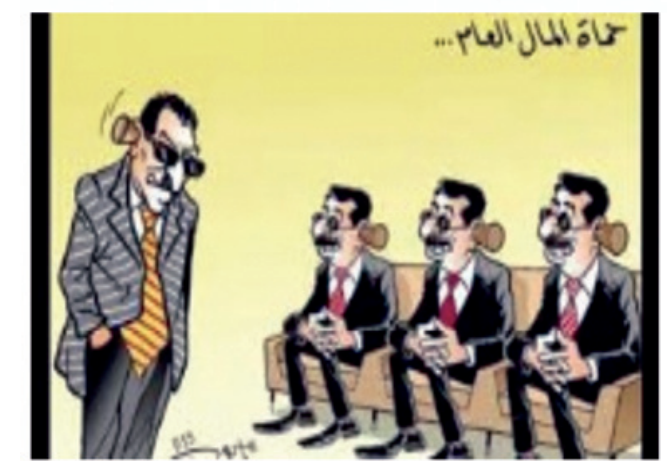

Figure 10. Protectors of the Public Treasury (Ayouni 2013).

Following the same line of thought, the cartoon in Figure 11 portrays a fat government official stealing a huge amount of public funds while pointing at a delinquent who he describes as "the most dangerous criminals." Remarkably, the disproportion of the characters' sizes connotes, on the one hand, the social and economical marginalization of the delinquent and it reflects, on the other hand, the corruption, greed and egoism of the government official.

Here, the cartoon calls upon the readers' critical thinking to deduce the connotative meaning, which points out that it is actually the government official who is the most dangerous criminal. In other words, if the delinquent boy stole the woman's bag, the government official has absconded with all population's 
money. The irony is the way politicians can sometimes point to law and order issues to distract attention from their own corruption. Based on Figures 10 and 11, and the frequency of appearance and circulation of these cartoons on the sample Facebook users' accounts of the study which exceeds $65 \%$ during the period under study, it is evident that the theme of financial corruption is a major concern for cartoonists as well as for the Tunisian public. In fact, the cartoon in Figure 12 represents the outcome of financial corruption in Tunisia after the 2011 revolution when ordinary Tunisians were the main victims.

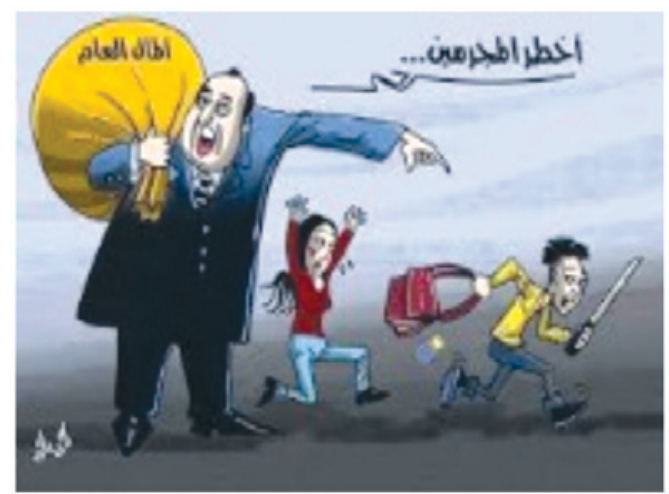

Figure 11. The Most Dangerous Criminals (Mhamdi 2014).

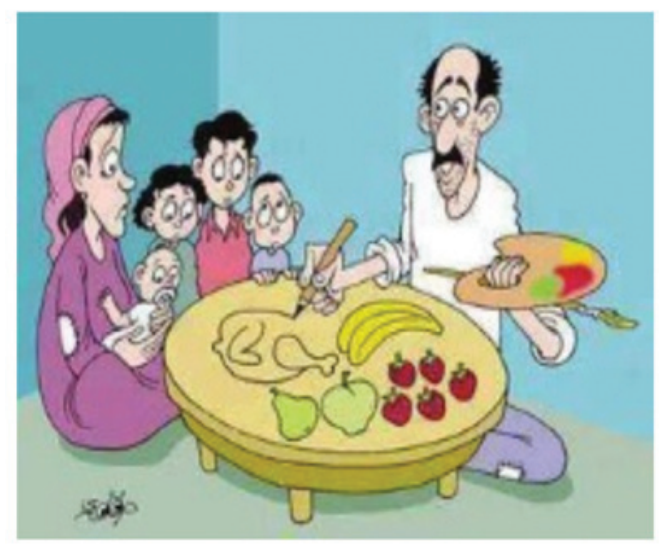

Figure 12. (Mhamdi 2014).

As made clear in Figure 12, a father is sitting with his wife and four children around a table where no food is available, but the father draws pictures of fruit 
and chicken. This image ironically summarizes the situation of poverty and hunger felt by a large number of Tunisians. As previously mentioned, what exacerbated this situation was the financial corruption that followed the revolution. Here, the imagery again suggests the futility of idealism if not translated into reality. We cannot eat the idea or image of food. The representation of hunger is represented at two levels: first by the cartoonist and second by the character in order to stress the miserable conditions of many Tunisians.

\subsection{THEME 7: POLITICAL UNCERTAINTY AFTER THE 2011 UPRISING}

The 2011 revolution in Tunisia, which resulted in the ousting of the president and signaled the outbreak of the so-called "Arab Spring" made the politics of countries experiencing uprisings more visible than ever. The 2011 Tunisian parliamentary elections brought about major changes in the political system and new political parties came to the forefront. This new status quo was characterized by chaos, disorder, and uncertainty. Many Tunisian politicians tried to justify this status as being a normal outcome of any post-revolution transitory phase. However, this justification was not always welcomed by the media.

Political cartoonists were no exception and they subtly tackled the political uncertainty of the transitory phase. Figure 13 clearly satirizes the "Tunisian political debate" where everyone is accusing his adversary of being "anti-revolution." The avatars in the panel below represent different animal figures accusing one another for being a conspirator against the revolution. Their physical differences and distinct facial expressions point to all political and socioeconomic actors of the Tunisian context at that time.

The diverse representation of the cartoon figures skillfully illustrates the total chaos, disorder, and anarchy of the political plight in Tunisia, where anyone could be easily accused of being "anti-revolution." This is revealed through the various anima-like figures with their different specific traits, shapes, facial expressions, and gestures. This situation is reminiscent of the "red scare" during the Cold War between the US and its rival, the Soviet Union, where anyone in the US could easily be denounced as a communist.

Additionally, Figure 14 explicitly warns against the overall outcome of the political uncertainty in Tunisia during its transitory phase. As is clearly represented in the cartoon, all political parties and leaders, whether the pros or the cons for the subsequent reforms after the revolution, are in the same boat and face the same fate. The photographic images in the cartoon specifically refer to the failure of the three-party coalition ruling the country at the time. As can be seen, the boat, the symbol of the country, is sinking and the political leaders of the coalition are also 
sinking and fighting the waves as each tries to save themselves. The sinking boat bears the names of the "Troika", the three-party coalition which was composed of three political parties governing Tunisia during that era.

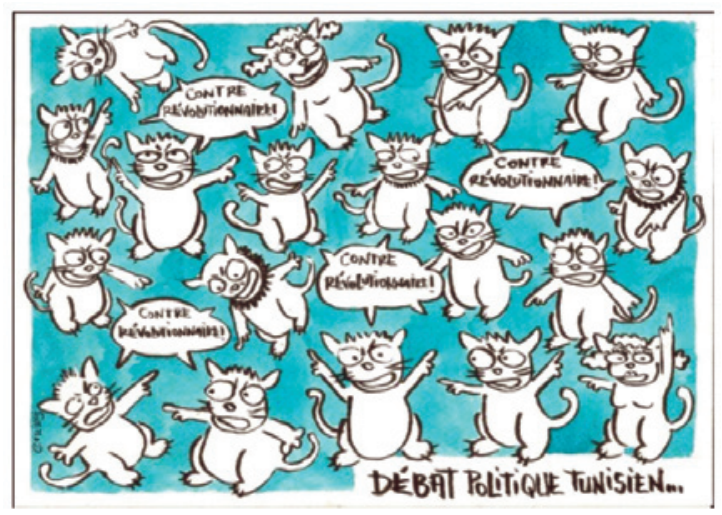

Figure 13. Tunisian Political Debate (Khiyari 2013).

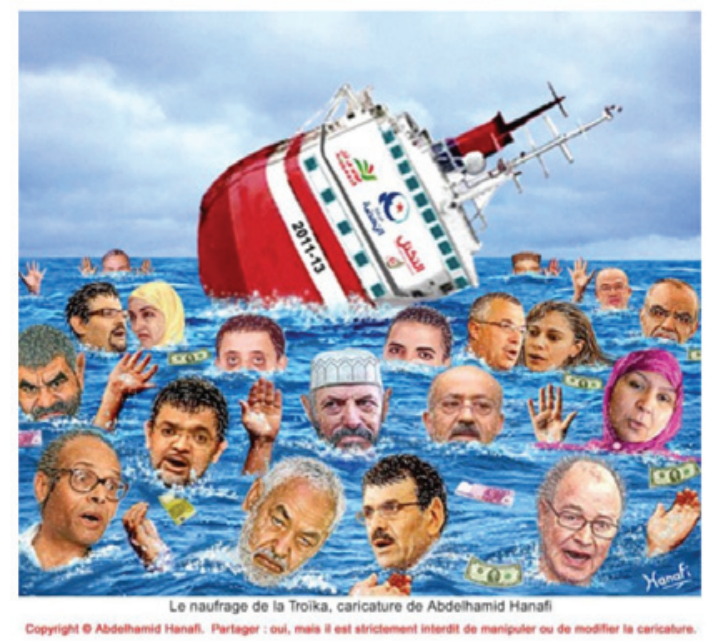

Figure 14. Troika is sinking (Hanafi 2013).

As shown in Figure 14, the cartoonist cautions against the probable fate of the political system in Tunisia and the collapse of the coalition in the transitory phase, which would lead to the collapse of the government. 


\subsection{THEME 8: THE TUNISIAN EXCEPTION TO THE "ARAB SPRING"}

The so-called "Arab Spring" refers to the series of uprisings that started in Tunisia on December 17, 2010, and spread rapidly across Egypt, Libya, and Syria. These uprisings resulted in the ousting of presidents, changing political systems, and the rise of some political parties at the expense of others. However, this series of uprisings also resulted in political chaos, social disorder, unemployment, insecurity, and rise of radicalism and terrorism.

It is evident that the situation was not identical in all the Arab countries that experienced uprisings. The conditions in most countries in the aftermath of uprisings were said to be worse than before, with the exception of Tunisia (Howard et al 2011: 6). The latter is considered to be the only successful case, which managed to be on the right track by building a democratic system. That system respects freedom, human rights, transparency, and its political focus is based on free elections and "checks and balances" between the executive, legislative, and judiciary powers. Figures 15 and 16 visibly represent Tunisia as an exceptional case in the middle of a barren "Arab Spring" that has recently turned into "Arab Autumn".

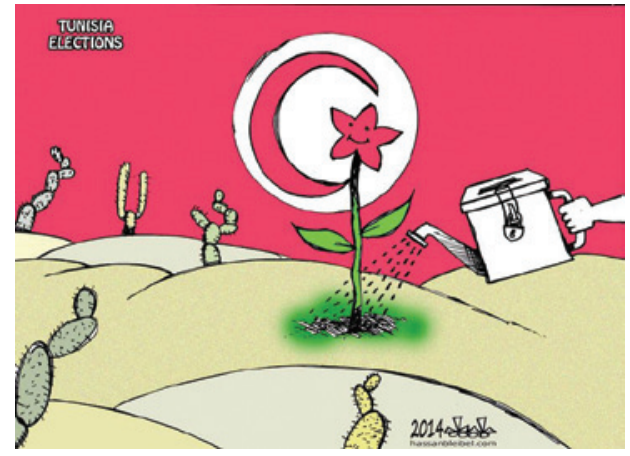

Figure 15. Tunisia Elections (Bleibel 2014)

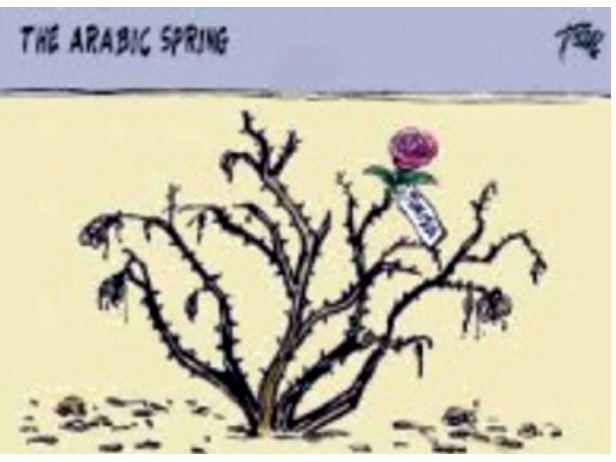

Figure 16. The Arabic Spring (Bleibel 2014)

As is shown in the two cartoons, Tunisia is metaphorically represented as a flourishing rose in the middle of a barren land. The cartoonists are positively representing the Tunisian experience as the only promising case in the gloomy atmosphere of the surrounding Arab countries and their uncertain futures. This representation calls for an optimistic message to Tunisian audiences and leaves room for hope of a better future.

Accordingly, it is worth mentioning that cartoonists do not only focus on negative issues through their cartoons, but also tackle positive themes. Being part 
of the media spectacle, political cartoonists are critical mirrors of their societies portraying socioeconomic and geopolitical conditions through their powerful medium that embeds visual and textual cues.

\section{CONCLUSION}

This study investigates the use of political cartoons in social media in the Tunisian context during the transitory phase after the 2011 uprising. The sample included 16 political cartoons, which were frequently shared and circulated through Facebook. The methodology used provided a framework for understanding the language and themes subsumed in visual and textual cues. Through the examination of the 16 cartoons, the study permitted the exploration of the broader socioeconomic and political context in Tunisia during the transitory phase following the 2011 revolution.

The findings of this study suggest that political cartoons were actively employed to mirror the socioeconomic and geopolitical conditions in Tunisia following the uprising of 2011. Tunisian cartoonists reflected the status quo during the transitory phase and subtly transmitted their critical messages through skillfully crafted cartoons. The cartoons sampled revealed an embedded approach that integrated verbal and non-verbal elements to generate meanings and transmit codes. The cartoonists' aim was mainly to satirically provoke and shock their audiences, leading them to question the reality of their situation and critically react to the status quo.

Additionally, the findings reveal the presence of eight main themes that were tackled by Tunisian cartoonists during the transitory phase. These predominant themes were of major concern not only to cartoonists, but also to the media in general and the Tunisian public. The themes were as follows: ousting the president, freedom and liberty, elections, threats to the revolution, the threat of terrorism and radicalism, financial corruption, political uncertainty, and the Tunisian exception to the so-called "Arab Spring."

\section{LIMITATIONS}

The study, nevertheless, has obvious limitations. First, the sample cartoons analyzed included only 16 online cartoons available on Facebook. Hence, the findings, especially those pertaining to the predominant themes, cannot be generalized since other themes were tackled by other cartoons appearing in print media or other social networks. Second, the study did not focus on one cartoonist and opted for a variety of cartoons from various cartoonists. This variety prevented the researcher from giving additional information on the cartoonists that may have influenced the context for analysis. 


\section{FUTURE STUDY}

Because of these limitations, the investigator suggests that further research be undertaken, in which a focus on one or two Tunisian cartoonists could be addressed. Additionally, enlarging the sample of cartoons under investigation could add new findings to the current literature. Eventually, an investigation into the use of political cartoons in Tunisian print media in the context of 2014 elections and its aftermath is highly recommended.

\section{REFERENCES}

Attardo, S., Eisterhold, J., Hay, J. and Poggi, I., 2003. "Multimodal markers of irony and sarcasm". Humor 16 (2): 243-260.

Ayouni, A. 2013. <https://www.facebook.com/chaker.mhamdi.1/groups> (Accessed 17 Dec. 2014)

Belkhadi, B. 2011. <https://www.facebook.com/chaker.mhamdi.1/groups> (Accessed 17 Dec. 2014)

Benoit, W.L., Klyukovski A., McHale, J., and Airne, D. 2001."A fantasy theme analysis of political cartoons on the Clinton-Lewinsky-Starr Affair". Critical Studies in Media Communication 18 (4): 377-394.

Bleibel, H. 2014. <https://www.facebook.com/chaker.mhamdi.1/groups> (Accessed 17 Dec. 2014)

Burns, E. 2007. "Infamous scribblers: The founding fathers and the rowdy beginnings of American journalism”. Public Affairs 69: 526-527.

Conners, J.L. 2005. "Visual representations of the 2004 presidential campaign". American. Behavioral Scientist 49 (3), 470-490.

Eisner, W. 2008. Comics and Sequential Art: Principles and Practices from The Legendary Cartoonist. New York: W.W. Norton and Company.

Eko, L. 2007. "It's a political jungle out there". International Communication Gazette 69 (3): 219.

El Refaie, E., 2003. "Understanding visual metaphor: The example of newspaper cartoons". Visual communication 2 (1): 75-95.

El Refaie, E. 2009. "Multiliteracies: How readers interpret political cartoons". Visual communication 8 (2): 181.

Fairclough, N. 1995. Media discourse. London: Arnold.

Giarelli, E., and Tulman, L. 2003. "Methodological issues in the use of published cartoons as data". Qualitative Health Research 13 (7): 945. 
THE USE OF POLITICAL CARTOONS DURING POPULAR PROTESTS: THE CASE OF THE 2011 TUNISIAN UPRISING

Gocek, F.M. 1998."Political cartoons as a site of representation and resistance in the middle east". Principal Cartoons in the Middle East. Ed. M. F. Gocek. Princeton: Markus Wiener Publishers. 1-13.

Greenberg, J. 2002. "Framing and temporality in political cartoons: A critical analysis of visual news discourse". Canadian Review of Sociology 39 (2): 181-198.

Groensteen, T. 2007. The System of Comics. Trans. Bart Beaty and Nick Nguyen. The United States of America: University Press of Mississippi.

Hanafi, A. 2013. <https://www.facebook.com/chaker.mhamdi.1/groups> (Accessed 17 Dec. 2014)

Hatfield, C. 2005. Alternative Comics: An Emerging Literature. The United States of America: University Press of Mississippi.

Howard, P.N., Duffy, A., Freelon, D., Hussain, M., Mari, W., and Mazaid, M. 2011. "Opening Closed Regimes: What Was the Role of Social Media During the Arab Spring?" Working Paper Project on Information Technology E Political Islam. 1-27.

Hutcheon, L. 1994. Irony's edge: the theory \& politics of irony. New York and London: Routledge.

Lefevre, P. 2012. "Mise en scene and framing". Critical Approaches to Comics Theories and Methods. Eds. M. J. Smith, and R. Duncan. New York and London: Routledge. 71-83.

Khatib, L. 2013. Image politics in the Middle East: the role of the visual in political struggle. London-New York: I. B. Tauris.

Khiyari, N. 2013. <https://www.facebook.com/chaker.mhamdi.1/groups> (Accessed 17 Dec. 2014)

Kress, G.R. and Van-Leeuwen, T. 1998. "Front Pages. (The critical) analysis of newspaper layout". Approaches to Media Discourse. Eds. A. Bell and P. Garrett. Oxford: Blackwell. 186-219.

Kress, G.R. and Van Leeuwen, T., 2006. Reading images: The grammar of visual design. London: Routledge.

Mahfouz, T. 2011. Arab culture, Vol.1: exploring the Arabic-speaking world through cartoons, satire, and bumor. USA: lulu.com

Majdoub, M. 2012.<https://www.facebook.com/chaker.mhamdi.1/groups> (Accessed 17 Dec. 2014)

McCloud, S. 1993. Understanding comics the invisible art. New York: HarperCollins Publishers.

Mechtat, M. 2011. <https://www.facebook.com/chaker.mhamdi.1/groups> (Accessed 17 Dec. 2014)

Medhurst, M.J. and DeSousa, M.A. 1981. "Political cartoons as rhetorical forms: A taxonomy of graphic discourse". Communication Monographs 48: 197-236. 
Mhamdi, C. 2014. <https://www.facebook.com/chaker.mhamdi.1/groups> (Accessed 17 Dec. 2014)

Mhamdi, C. 2016. "Transgressing media boundaries: News creation and dissemination in a globalized world". Mediterranean Journal of Social Sciences 7 (5): 272-277.

Mhamdi, C. 2017a. "Framing 'the Other' in Times of Conflicts: CNN's Coverage of the 2003 Iraq War". Mediterranean Journal of Social Sciences 8 (2): 147-153.

Mhamdi, C. 2017b. "Interpreting Games: Meaning Creation in the Context of Temporality and Interactivity". Mediterranean Journal of Social Sciences 8 (4): 39-46.

Morris, R. 1992. "Cartoons and the political system: Canada, Quebec, Wales, and England". Canadian Journal of Communication 17 (2): 62.

Movement, C. 2012. <https://www.facebook.com/chaker.mhamdi.1/groups> (Accessed 17 Dec. 2014)

Ouerteni, O. 2014. <https://www.facebook.com/chaker.mhamdi.1/groups> (Accessed 17 Dec. 2014)

Romero, G. and Dahlman, L. 2012. "Justice framed: Law in comics and graphic novels". Law Text Culture 16 (1): 3-32.

Samson, A.C. and Huber, O., 2007. "The interaction of cartoonist's gender and formal features of cartoons". Humor-International Journal of Humor Research 20 (1): 1-25.

Sani, I., Hayati, A.M., Mohamad, A.A., and Sathi, A.F. 2012a. "Linguistic analysis on the construction of satire in Nigerian political cartoons: The example of newspaper cartoons". Journal of Media and Communication Studies 4 (3): 52-59.

Sani, I., Hayati, A.M., Mohamad, A.A., and Sathi, A.F. 2012b. "The role of humor in the construction of satire in Nigerian political cartoons". Online Journal of Communication and Media Technologies 2 (3): 148-165.

Selden, R. 1989. Practicing Theory and Reading Literature. Kentucky: University Press of Kentucky.

Stouter, E., Wills, D. and Marlette, D. 2008. "Infestation and eradication: Political cartoons and exterminationist rhetoric in the war on terror". Global Media Journal: Mediterranean Edition 3 (1): 11-23.

Totry, M. and Medzini, A. 2013. "The use of cartoons in popular protests that focus on geographic, social, economic and political issues". European Journal of Geography 4 (1): 22-35.

Tsakona, V. 2009. "Language and image interaction in cartoons: Towards a multimodel theory of humor". Journal of Pragmatics 41 (6): 1171-1188.

Zaghbi, A. 2011.<https://www.facebook.com/chaker.mhamdi.1/groups> (Accessed 17 Dec. 2014)

Wozniak, M. 2014. "Mirror, mirror on the wall: political cartoons of the Arab spring". Hemispheres 29 (6): 5-22. 